\title{
O Ensino Fraternal e Humanista Como Pressuposto Democrático e a Efetiva Integração dos Direitos Humanos na Agenda Educacional até 2030
}

\begin{abstract}
Fábio da Silva Veiga
Professor de Direito da Universidade de Almería. Presidente do Instituto Iberoamericano de Estudos Jurídicos - Iberojur. Coordenador do Pós-Doutorado em Direito Público da Universidade de Santiago de Compostela. Doutor em Direito pela Universidade de Vigo. Pesquisador da Capes no Exterior - Universidade de Alcalá, Madrid. Mestre em Direito pela Universidade do Minho. http://lattes.cnpq.br/6788369152739927. https://orcid.org/0000-00029986-7813. fabiojus@gmail.com

\section{Vivian Rodrigues Madeira da Costa}

Mestre em Governança e Direitos Humanos pela Universidade Autônoma de Madrid. Mestranda em Direito Público pela Universidade de Sevilha. Investigadora da área científica de Direito Internacional do Instituto Iberoamericano de Estudos Jurídicos e advogada. http://lattes.cnpq.br/5262735822694900. https://orcid.org/0000-0002-1618-5957. vivianrmdacosta@gmail.com
\end{abstract}

Como fruto do trabalho do Fórum Mundial sobre a Educação realizado em 2015 e liderado pela Organização das Nações Unidas para a Educação, a Ciência e a Cultura, foi publicada no cenário internacional a Declaração de Incheon e o Marco de Ação até 2030, rumo a uma educação de qualidade inclusiva e equitativa e à educação ao longo da vida para todos. Esta Declaração, de significativa importância no âmbito internacional, deve ter um reflexo necessário nas democracias constitucionais contemporâneas, de forma a instituir definitivamente o conteúdo dos direitos humanos tanto de forma objetiva, como parte da matéria constante no programa curricular, quanto de maneira a nortear a política de ensino, a partir da introdução de importantes medidas de justiça social. Com efeito, o ensino precisa ser mais abrangente, livre e inclusivo, sendo o acesso à educação um direito humano e, portanto, reconhecidamente essencial ao livre-desenvolvimento humano. O conteúdo humanista e fraterno precisa ser alçado ao debate político e não ser relegado ao campo puramente da ética, muito embora essa seara também seja juridicamente importante. 0 próprio princípio da fraternidade, porém, traz consigo uma força axiológica passível de objetividade e não deve ser olvidado como componente importante da famosa tríade principiológica revolucionária, a modular e moldar a liberdade e a igualdade. Da mesma forma, a instrução é pressuposto para a efetividade e a legitimidade democráticas, uma vez que não pode haver um governo do povo sem educação e, assim, possibilidade de manifestação livre da vontade. Ao longo do presente artigo buscar-se-á abordar tais aspectos de maneira a defender a inclusão dos direitos humanos na agenda educativa, constituindo um sistema de ensino fraternal e humanista a ser instituído até 2030.

Palavras-chave: Ensino. Fraternal. Direitos humanos. Democracia.

FRATERNAL AND HUMANIST TEACHING AS A DEMOCRATIC PREMISE AND THE INTEGRATION OF HUMAN RIGHTS IN THE EDUCATIONAL AGENDA UNTIL 2030

ABSTRACT

As a result of the work of the World Education Forum held in 2015 and led by the United Nations Educational, Scientific and Cultural Organization, the Incheon Declaration and the action milestone until 2030 was published on the international scenario, towards an inclusive and equitable quality education and lifelong education for all. This Declaration, of significant importance at the international level, must have a necessary reflection in contemporary constitutional democracies, in order to definitively implement the content of human rights both objectively, as part of the subject matter in the curriculum, and in order to guide the teaching policy, starting with the introduction of important social justice measures. Indeed, education needs to be more comprehensive, free and inclusive, being the access to education a human right and, therefore, recognized as essential to free human development. The humanistic and fraternal content needs to be raised to political debate and not be relegated to the purely ethical field, although this area is also legally important. However, the very principle of fraternity brings with it an axiological force capable of objectivity and should not be overlooked, as an important component of the famous revolutionary principled triad, to modulate and shape freedom and equality. Likewise, instruction is a prerequisite for democratic effectiveness and legitimacy, since there cannot be a government of the people without education and, thus, the possibility of free expression of will. Throughout this article, we will seek to address such aspects, in order to defend the inclusion of human rights in the educational agenda, constituting a fraternal and humanistic education system to be implemented until 2030.

Keywords: Teaching. Fraternal. Human rights. Democracy. SUMÁRIO

1 Introdução. 2 Por um sistema de ensino humanista e fraternal. 3 A educação no domínio dos Direitos Humanos e a consideração do princípio da fraternidade. 4 Educação como corolário lógico do Estado Democrático de Direito. 5 A proposta das Nações Unidas de um modelo educacional para o século 21. 6 Conclusão. 7 Referências. 


\section{Humanos e \\ Democracia}

\section{INTRODUÇÃO}

No cenário social sabe-se que o acesso à educação é reconhecidamente um direito humano básico, tal qual preconiza a Declaração Universal dos Direitos do Homem. Com efeito, este documento político internacional também assevera que todos os seres humanos nascem livres e iguais em dignidade e direitos, sendo dotados de razão e consciência e devendo agir em relação uns aos outros com espírito de fraternidade. ${ }^{1}$

É mister destacar que, no bojo de tal declaração, de relevância singular no âmbito internacional e com importantes reflexos nos ordenamentos jurídicos das democracias constitucionais contemporâneas, todo ser humano tem direito à liberdade de opinião e expressão, assim como à instrução. Ora, se não há educação e acesso ao ensino, tampouco seria possível e viável a livre-expressão dos indivíduos.

Sobre a educação, declara-se, ainda, que esta deve ser gratuita, ao menos nos graus elementares e fundamentais, sendo obrigatória a instrução elementar. Da mesma forma, afirma-se que a instrução técnico-profissional deverá ser acessível a todos, sendo a instrução superior baseada no mérito.

Merece destaque, igualmente, a afirmação do artigo XXVI da referida Declaração, segundo o qual "a instrução será orientada no sentido do pleno desenvolvimento da personalidade humana e do fortalecimento do respeito pelos direitos humanos e pelas liberdades fundamentais", e sobre tal instrução a ser promovida pelos Estados Nacionais, frisa-se que esta "promoverá a compreensão, a tolerância e a amizade entre todas as nações e grupos raciais ou religiosos, e coadjuvará as atividades das Nações Unidas em prol da manutenção da paz". ${ }^{2}$

A partir de tais afirmações emana e se consolida uma diretriz para a política de ensino, de forma a estabelecer a educação como elemento imprescindível para a própria manutenção da paz entre os povos. Ademais, sob a perspectiva do indivíduo, a instrução passa a ser internacionalmente reconhecida como direito essencial ao seu livre-desenvolvimento, com extensão ao direito de participar livremente da vida cultural da comunidade, de fruir das artes e de ser parte do progresso científico e de seus benefícios.

Observa-se, também, o objetivo de preconizar um modelo educativo de caráter fraternal, pensado como projeto de pacificação social e que inclua os direitos humanos, de forma a integrá-los na sua prática, assim como a instruir acerca do conteúdo destes direitos. O processo de integração dos direitos humanos no modelo educativo tem como resultado um projeto de ensino acessível, plural, abrangente e livre, de forma que estes conceitos jurídicos, incorporados ao sistema, também possam ser transferidos aos destinatários de forma implícita e explícita.

No âmbito do ordenamento jurídico brasileiro, o direito à educação é reconhecido como um direito social, juntamente com a saúde, a alimentação, o trabalho, a moradia, o transporte, o lazer, a segurança, a previdência social e a proteção à maternidade e à infância. Sem adentrar na seara da discussão acerca da nota de fundamentalidade desse direito, clas-

\footnotetext{
Cfr. Nações Unidas. Declaração Universal dos Direitos do Homem [Em linha], 1948. Disponível em: https://nacoesunidas. org/wp-content/uploads/2018/10/DUDH.pdf. Acesso em: 15 mar. 2010.

2 Idem.
} 
sificado como direito social e cuja efetivação perpassa por um sistema complexo e interligado aos demais direitos sociais e fundamentais, parte-se do pressuposto que o acesso à educação é essencialmente um direito humano.

Assim, no decorrer do presente artigo procura-se tecer uma análise sobre a educação no domínio dos direitos humanos e com a incorporação do princípio da fraternidade como parte da busca por um sistema de ensino humanista e fraternal. Busca-se, juridicamente, retornar às origens e reestruturar o equilíbrio concebido por meio de direitos básicos guiados pela fraternidade, como princípio regulador da liberdade e da igualdade, possibilitando o triunfo dos direitos humanos. ${ }^{3}$

Além disso, também visa-se a demonstrar como a instrução é, inegavelmente, um pressuposto fático e corolário lógico do verdadeiro exercício democrático, de forma que não há de se falar em estado de direito sem a existência efetiva deste direito reconhecidamente humano. Frisa-se, ademais, que a educação está intrinsecamente relacionada com uma série de outros direitos humanos, fundamentais e sociais, de forma a ocupar posição de destaque na estrutura fundacional das democracias constitucionais contemporâneas.

\section{POR UM SISTEMA DE ENSINO HUMANISTA E FRATERNAL}

Sendo o sentido etimológico do vocábulo humanista, referente a uma doutrina centrada no indivíduo humano e na humanidade, um projeto educativo que se proponha nesta seara, tem-se como objetivo valorizar os direitos humanos. Ayres Britto (2012) plasmou esse entendimento na sua obra, quando fez refletir nas seguintes palavras:

[...] toda essa histórica e formal proclamação de ser a pessoa humana portadora de uma dignidade "inata" é o próprio Direito a reconhecer o seguinte: a humanidade que mora em cada um de nós é em si mesma o fundamento lógico ou o título de legitimação de tal dignidade. Não cabendo a ele, Direito, outro papel que não seja o de declará-la.4

Vale a pena destacar, igualmente, que o termo humanitário é referente a tudo o que concerne à humanidade, compreendida como o conjunto dos seres humanos e o que é relativo à natureza humana. Desta forma, também se poderia falar de educação humanitária de modo a considerar, por conseguinte, os aspectos, circunstâncias e elementos próprios dos direitos caros ao homem e da fraternidade como necessariamente parte do processo educativo.

Cabe ressaltar, ainda, que a palavra humanidade carrega consigo, axiologicamente, a ideia do que é ligado à benevolência, assim como o vocábulo humanitário o faz. Uma educação humanitária, portanto, também pode ser aquela que inclua aspectos próprios da valorização do ser humano, de forma a reforçar os valores da eticidade, moralidade e fraternidade

\footnotetext{
Diferentemente, Paulo Ferreira da Cunha adota uma posição intermediária sobre a aplicação da fraternidade no Direito, denominando de "Direito Fraterno". Nesse sentido, indaga a aplicação dos paradigmas do Direito Natural e do Direito Positivo, ambos norteadores da ciência jurídica, e reflete acerca de um novo paradigma - o Direito Fraterno. Desse modo, pretende ir além da formalidade daqueles e chegar a um modelo informal, ou seja, o paradigma jurídico-político dos direitos humanos. Cfr. CUNHA, Paulo Ferreira. Do Direito Natural ao Direito Fraterno. In: Revista de Estudos Constitucionais, Hermenêutica e Teoria do Direito (RECHTD), jan./jun. 2009. p. 78-86. ISSN: 2175-2168. Disponível em: http://www.revistas. unisinos.br/index.php/RECHTD/article/view/5138. Acesso em: 23 mar. 2020.

${ }^{4}$ Cfr. BRITTO, Carlo Ayres. O humanismo como categoria constitucional. Belo Horizonte: Ed. Fórum, 2012. p. 25.
} 


\section{Humanos e}

Democracia

na construção das relações interpessoais, assim como os valores próprios da sustentabilidade e, inclusive, do respeito a outras espécies, apesar de o conceito estar mais atrelada à questão da beneficência.

Nesse diapasão, é interessante recordar que, dos três princípios auspiciados pela Revolução Francesa e que nortearam, de igual maneira, o arcabouço jurídico contemporâneo, quais sejam, liberdade, igualdade e fraternidade, parece-nos que a este último se atribuiu inicialmente um papel de menor expressividade ou materialidade na criação do direito, talvez pelo carácter mais relativo às emoções e, aparentemente, de menor objetividade.

Assim, o ideal da fraternidade, parte da importante tríade proclamada durante a Revolução Francesa, ocupava um lugar de destaque na filosofia política revolucionária e na teoria jurídica e social antecedente aos direitos humanos. No contexto do pós-guerra e na dinâmica internacional e estatal, no entanto, afigura-se que pouco a pouco perdeu importância, enquanto os ideais de igualdade e liberdade foram explorados e desenvolvidos, muito embora se faça menção expressa a tal ideal na Declaração Universal dos Direitos do Homem de 1948.

Com efeito, cada princípio não prescinde do outro para seu próprio desenvolvimento individual, ou seja, há a necessidade de um desenvolvimento harmônico entre todos para a própria concretização individual. Não obstante, o ideal de fraternidade geralmente não aparece de forma objetiva em documentos legais e políticos, talvez pelo seu aparente ônus excessivamente emocional conforme afirmado, de modo que foi relegado ao campo da ética ou inspirou outros termos como solidariedade, expressos em alguns documentos jurídicos.

Outras expressões e termos, como o anteriormente citado, todavia, não cobrem profundamente o sentido mais amplo da fraternidade, uma vez que, por vezes, ressaltam a questão do sentimento comunitário, sobre o qual estaria baseada uma concepção de coesão e unidade social, como assevera Amaya. ${ }^{5}$ Esta é igualmente importante, mas de alguma maneira está mais relacionada à questão da beneficência, a qual, por sua vez, está atrelada a uma perspectiva vitimológica que não se refere à essência da fraternidade.

Filosoficamente, a ideia de fraternidade estabelece que o homem, como animal político, escolhe conscientemente viver em sociedade e, portanto, para que essa vida seja harmônica, deve estabelecer uma relação de igualdade com seus pares, pois na essência e na natureza não há nada que os diferencie hierarquicamente, como ocorre entre irmãos (de acordo com a definição etimológica do termo).

Esse conceito, portanto, é a essência da configuração completa e da própria definição de cidadania, permeada pela pura ideia de igualdade. Assim, pode-se observar que, de certa forma, fraternidade, liberdade e igualdade não sobrevivem e têm seu pleno desenvolvimento independentemente, pois, para a manifestação de cada um, os outros devem igualmente ser válidos. Na realidade, o melhor conceito de vida em sociedade não pode ser concretizado sem o resultado equilibrado dessa fórmula, uma vez que não é possível se falar de igualdade total sem respeito pelos demais e levando-se em consideração a fraternidade, sendo a liberdade limitada por esses dois outros aspectos e existindo a partir deles.

AMAYA, Amalia. La Relevancia de la Fraternidad. In: Yale Law School [Em linha], p. 5. Disponível em: https://law.yale.edu/ sites/default/files/area/center/kamel/sela17_amaya_cv_sp.pdf. Acesso em: 24 mar. 2020. 
Com efeito, a fraternidade teve algum reconhecimento constitucional, aparecendo expressamente no preâmbulo da Constituição Francesa de 1848, juntamente com os princípios de igualdade e liberdade. No contexto do pós-guerra, contudo, observa-se a consagração de outro valor que assume relevância fundamental: a dignidade da pessoa humana como valor universal, principalmente a partir dos contornos jurídicos conferidos pela Declaração Universal dos Direitos Humanos, que utiliza esse conceito para definir a atributo imanente ao ser humano para o exercício da liberdade e dos direitos como garantia de uma existência plena.

A dignidade da pessoa humana tem raízes filosóficas, sendo o início de sua concepção proveniente da noção de dignidade individual, oriunda do próprio cristianismo. No século 18 , com Immanuel Kant, a dignidade da pessoa humana já havia sido filosoficamente consolidada, partindo da primazia de que o ser humano nunca fosse visto ou usado como um meio de alcançar outros fins, mas sempre como um fim em si mesmo. A partir daí também vai se consolidando o imperativo categórico de guiar as relações jurídicas e sociais a partir da valorização do ser individual, constituindo um valor básico e universal.

Como é possível observar, o termo fraternidade tem um significado etimológico implícito relevante e seu estudo e aplicação devem ser restabelecidos como uma categoria política no centro da reflexão, não como um simples sentimento nobre, como afirma Enrique del Persio, ${ }^{6}$ quem também defende que devemos deixar os vícios e retornar às formas puras: a igualdade, para ser assim, pressupõe (é claro que de forma conflituosa) a liberdade, e a fraternidade pressupõem a igualdade, impondo-Ihes tal dinâmica e tornando a liberdade uma libertação e a igualdade justiça social.

Nesse âmbito, o professor Baggio afirma:

Como es sabido, de los tres principios la fraternidad es aquel que al parecer menos se puso en práctica. Pero, por otro lado, también la libertad y la igualdad se aplicaron sólo parcialmente, expuestos continuamente a un doble riesgo de degeneración: la libertad en el arbitrio de la ley del más fuerte, la igualdad en la masificación. Si se dejan cada una por su cuenta, la libertad y la igualdad se ponen la una contra la otra: proclamadas juntas por la Revolución francesa, dieron vida, sucesivamente, a dos sistemas culturales, económicos y políticos, opuestos. En realidad, para vivir bien, necesitamos de ambas. Y es precisamente en estos últimos años que, desde diferentes partes, se empezó a formular la pregunta: los fracasos de la libertad y de la igualdad, ¿no dependerán precisamente del hecho de que la fraternidad no ha sido vivida? De hecho, la fraternidad contiene en sí, sea el elemento de la igualdad (los hermanos están a la par entre ellos), sea el elemento de la libertad (cada uno de los hermanos es diferente del otro). Por lo tanto actúa -pero no sólo - como principio regulador de los otros dos. ${ }^{7}$

\footnotetext{
PERCIO. Enrique del. Fraternidad, conflicto y realismo político. Claves para pensar la integración desde América Latina. In: Teoría y Praxis, n. 21, p. 9, jun./dic. 2012. Disponível em: http://rd.udb.edu.sv:8080/jspui/bitstream/11715/857/1/1-fraternidad-conflicto-y-realismo-politico.pdf. Acesso em: 15 fev. 2020.

7 Leia-se a tradução livre: "Como é sabido, dos três princípios a fraternidade é a que parece ter sido menos praticada. Mas, por outro lado, liberdade e igualdade também eram apenas parcialmente aplicadas, continuamente expostas a um duplo risco de degeneração: liberdade, a critério da lei dos mais fortes, igualdade na massificação. Se cada um é deixado para si, liberdade e igualdade são colocadas uma contra a outra: proclamados juntos pela Revolução Francesa, eles deram vida, sucessivamente, a dois sistemas culturais, econômicos e políticos opostos. Na verdade, para viver bem, precisamos de ambos. E é precisamente nos últimos anos que a pergunta começou a ser feita de diferentes partes: Os fracassos da liberdade e da igualdade não dependerão precisamente do fato de a fraternidade não ter sido vivida? De fato, a fraternidade contém em si mesma, seja o elemento da igualdade (os irmãos estão em pé de igualdade), ou o elemento da liberdade (cada irmão é diferente do outro). Portanto, atua - mas não apenas - como princípio regulador dos outros dois." In: Entrevista al Profesor Antonio María Baggio, por GONZALEZ, Roberto Veiga. En el horizonte de la fraternidad. Disponível em: http://www. uca.edu.ar/uca/common/grupo75/files/antonio_baggio.pdf. Acesso em: 15 fev. 2020.
} 


\section{Democracia}

Apesar de outras noções terem gerado um deslocamento do conceito de fraternidade, existem aproximações na literatura filosófica, política e jurídica contemporânea, incluindo concepções liberais, como também é o caso das teorias de John Rawls e Ronald Dworkin, nas quais a fraternidade ocupa um lugar importante na construção de uma teoria da justiça, a fim de impor uma exigência clara que deve satisfazer a estrutura básica da sociedade, bem como uma função fundamental na justificação da legitimidade política, respectivamente.

Assim, a legitimidade de uma comunidade política depende de ser uma verdadeira comunidade fraterna, ou seja, um Estado é legítimo se sua estrutura e práticas constitucionais forem tais que seus cidadãos tenham uma obrigação geral de obedecer decisões legais que impõem deveres. ${ }^{8}$ Com razão, a fraternidade parece voltar a ser levantada como princípio norteador, dotado de importância, além dos contornos meramente emocionais, pois possui relevância política e social e, aliada aos demais princípios, pode garantir uma estrutura pacífica de convivência em sociedade.

Dessa maneira, à primeira vista, a fraternidade parece ser muito diáfana, pouco paupável, mas pode ser transportada para o campo da realidade no espaço público de discussão e aplicação política, conforme necessário para uma convivência harmoniosa em sociedade. Os homens, universalmente, não podem ser absolutamente tratados como iguais se não se mobilizarem para o sentimento de fraternidade entre si, e não serão totalmente livres se o sentimento fraternal não permear os relacionamentos interpessoais.

O discurso fraterno está no campo da ética, mas também além. Sem ignorar a importância desta e mesmo da moral no contexto jurídico, uma vez que fazem parte dos sistemas jurídicos contemporâneos, o que se pretende é dar força normativa e objetiva à fraternidade, reestruturando a famosa tríade com liberdade e igualdade, para que o ser humano possa ser valorizado não apenas por sua dimensão individual, mas a partir da característica essencial de fazer parte da família humana.

\section{A EDUCAÇÃO NO DOMÍNIO DOS DIREITOS HUMANOS E A CONSIDERAÇÃO DO PRINCÍPIO DA FRATERNIDADE}

Nesse contexto, o processo educativo não pode se furtar dos elementos próprios do princípio da fraternidade, de forma que tal valor permeie também as políticas públicas de ensino, bem como o conteúdo das cartilhas escolares. De igual maneira, coloca-se a consideração por um processo de educação que seja humanitário e valorize os direitos humanos. Percebe-se, nessa linha, a possibilidade de aplicação deste raciocínio a partir de duas perspectivas, a seguir tratadas.

O primeiro aspecto demarca-se no sentido de se considerar a inclusão de tais princípios e conceitos no processo educativo, por meio da estruturação política deste próprio processo sob a ótica humanitária e fraternal. O resultado é a busca por um sistema inclusivo, plural, capaz de abraçar o maior número possível de alunos, a ser executado de forma ampla, acessível, universal e adaptável às inúmeras minorias. A perspectiva seguinte é a de que os valores

Cfr. AMAYA, Amalia. passim. 
humanitários e fraternais possam ser parte do conteúdo a ser ministrado, de forma que o estudo e os conteúdos próprios da ética, dos direitos humanos e da sustentabilidade, possam ser transmitidos aos alunos.

Indubitavelmente, esse procedimento jurídico e político tem o condão de mudar os paradigmas e a dinâmica social de forma integral e holística, uma vez que se aplica no campo social um processo educativo de transformação que, por sua natureza, confere um impacto amplo em todo o estrato da sociedade. Assim sendo, a consideração jurídica do princípio da fraternidade, bem como a valorização e inclusão da pauta humanitária no programa nacional de ensino (políticas públicas verticais), de forma prática, também são um sustentáculo do próprio Estado Democrático de Direito.

\section{EDUCAÇÃO COMO COROLÁRIO LÓGICO DO ESTADO DEMOCRÁTICO DE DIREITO}

É possível, igualmente, extrair o valor essencial de um sistema que seja democrático a partir do próprio significado etimológico do vocábulo democracia, cujas raízes referem-se ao governo de titularidade do povo. Como bem ressalta o cientista político italiano Giovanni Sartori, ${ }^{9}$ a democracia é essencialmente um sistema e regime político pelo qual o poder emana do povo, mas dessa afirmação também se desdobram importantes questionamentos sobre a delimitação e a composição desse povo e o processo de atribuição e manifestação de seu poder, por exemplo.

Com efeito, parece haver um consenso de que, a partir de um ponto de vista operativo, a democracia ocorre por meio da manifestação da vontade de uma maioria limitada ou moderada do corpo de cidadãos em sua plenitude, de forma que o sistema tampouco se converta em uma experiência de imposição da vontade predominante em detrimento da minoria. Dessa maneira, a aplicação do princípio da maioria relativa começa a delinear e materializar um modelo mais equilibrado e justo.

Ademais, essa vontade popular será expressada no processo eleitoral, a partir da opinião pública e das eleições, razão pela qual se afirma, com mais técnica, que o povo detém a titularidade do poder, mas não seu exercício. Além disso, sobre o fenômeno das eleições e da opinião pública, Sartori (2009) destaca um raciocínio deveras relevante, conforme se transcreve a seguir:

Se dice que las elecciones deben ser libres. Sin duda, pero también las opiniones deben ser libres, es decir, libremente formadas. Si las opiniones se imponen, las elecciones no pueden ser libres. Un pueblo soberano que no tiene nada que decir de sí mismo, un pueblo sin opiniones propias, cuenta menos que el dos de copas. Por tanto, todo el edificio de la democracia se apoya en la opinión pública y en una opinión que surja del seno de los públicos que la expresan. Lo que significa que las opiniones en el público tienes que ser también opiniones del público, opiniones que en alguna forma o medida el público se forma por sí solo. ${ }^{10}$

\footnotetext{
9 Cfr. SARTORI, Giovani. La Democracia en Treinta Lecciones. México: Santillana Ediciones Generales, 2009. p. 15.

${ }^{10}$ Tradução livre: "Dizem que as eleições devem ser livres. Sem dúvida, mas as opiniões também devem ser livres, isto é, livremente formadas. Se opiniões são impostas, as eleições não podem ser livres. Um povo soberano que não tem nada a dizer sobre si mesmo, um povo sem suas próprias opiniões, conta menos do que o dois de copas. Portanto, todo o edifício da democracia é baseado na opinião pública e em uma opinião que emerge do seio do público que a expressa. $O$ que significa que as opiniões do público também devem ser opiniões do público, opiniões que de alguma forma ou medida o público forma por conta própria." Ibid., p. 31
} 
Depreende-se com clareza do texto destacado a concepção segundo a qual a opinião pública, para que assim o seja de fato, precisa ser livre e autêntica, original e espontânea. Dessa maneira, na chamada era da pós-verdade, na qual pululam a divulgação de falsas notícias, as quais se alastram com imensa rapidez pelos meios de telecomunicação atuais, esse pensamento é ainda mais relevante, de maneira a levantar o questionamento sobre a importância da autenticidade da opinião pública para a própria garantia democrática.

Sem, todavia, a pretensão de esgotar o tema sobre os fenômenos sociológicos supramencionados, os quais, em realidade, são parte da própria dinâmica e problemática humanas, sendo apenas maximizados mediante as novas tecnologias, é mister deter a atenção no aspecto fundamental acerca da opinião pública e sua autenticidade. Indubitavelmente, para opinar é preciso conhecer, é preciso saber, é preciso deter certas ferramentas e ter conhecimento de determinados fatos.

Nesse sentido, o caminho para que se tenha conhecimento mínimo e o desenvolvimento dos instrumentos necessários para a manifestação da opinião pública perpassa necessariamente pelo direito humano à educação. A resposta apresenta-se de forma evidente e o fato comprova-se empiricamente. Um povo livre para opinar é aquele que tem acesso à educação e, a partir da instrução, em consonância com a efetividade de outros direitos, pode ser, de fato, livre, manifestar sua vontade não viciada e, assim, opinar com liberdade.

Se sem opinião autêntica não existe verdadeiramente a opinião pública, imprescindível na arena democrática, e sem educação não pode haver opinião livre, a conclusão parece ser clara: sem educação popular não existe democracia. A afirmação é lógica, mas possui extensos desdobramentos e seu impacto é fundamental, frisando-se que um Estado Democrático de Direito, como tal, é entendido como aquele em que há a prevalência de lei por intermédio da aplicação do princípio democrático, bem como do pluralismo.

Ao constatar-se que a maioria, ou mesmo grande parte de um corpo popular, é privada das ferramentas básicas necessárias para o exercício democrático, começa-se a questionar esse estado de direito que se afirma existir em muitas experiências constitucionais contemporâneas. Segundo Rohling e Valle (2016), a educação multicultural e a equidade são princípios da teoria da justiça, sobretudo ao se analisar a doutrina de Rawls, que podem e devem ser transpostos à noção de justiça escolar, criticando a escola como possível instituição reprodutora de desigualdades sociais. ${ }^{11}$

Assim afirmam os autores supracitados:

De fato, a partir da teoria da justiça de Rawls, ideias como justiça, igualdade e equidade, que formam uma complexa compreensão do que é uma sociedade justa, passaram a integrar invariavelmente as mais diversas abordagens destinadas ao cotejo da educação e das práticas políticas e econômicas sociais. (...) Nesse sentido, se presumirmos a existência das instituições que requisitam os princípios de justiça e se admitirmos que a injustiça se caracteriza nas desigualdades sociais que não sejam vantajosas para todos, mais claramente poderemos entender que apenas são aceitáveis desvantagens sociais que be-

\footnotetext{
${ }^{11}$ Cfr. ROHLING, Marcos; VALLE, Ione Ribeiro. Princípios de Justiça e Justiça Escolar: a educação multicultural e a equidade. In: Cadernos de Pesquisa, v. 46, n. 160, abr./jun. 2016, p. 386-409.
} 
neficiem a alguns mais bem colocados no esquema se dessas desvantagens resultarem benefícios para aqueles mais à base na pirâmide social. Isto é, a justiça das expectativas dos mais bem situados socialmente relaciona-se diretamente com o grau de elevação das expectativas dos que estão em posições mais desfavorecidas, de tal modo que as desigualdades são justas se forem vantajosas para os menos favorecidos. ${ }^{12}$

No seguimento do apresentado, no qual se compreende a educação como pressuposto da legitimidade política, como sustentáculo do próprio Estado de Direito, sendo necessária para a verdadeira justiça social, tal concepção faz parte de um paradigma preconizado pelos juristas contemporâneos, cujo panorama é auspiciado pelas Nações Unidas de forma a incentivar um modelo universal de educação para os direitos humanos e sobre o próprio conteúdo desses direitos.

\section{A PROPOSTA DAS NAÇÕES UNIDAS DE UM MODELO EDUCACIONAL PARA O SÉCULO 21}

Como fruto do trabalho desenvolvido no âmbito do Fórum Mundial de Educação, realizado no ano de 2015 e liderado pela Organização das Nações Unidas para a Educação, a Ciência e a Cultura (Unesco), foi publicada no cenário internacional a Declaração de Incheon e - Marco de Ação até 2030, rumo a uma educação de qualidade inclusiva e equitativa e à educação ao longo da vida para todos, como afirma o referido documento.

Dessa forma, a partir de tal Declaração é consolidada uma visão internacional comum sobre um novo paradigma a ser adotado no âmbito educacional, em consonância com os Objetivos do Desenvolvimento Sustentável, conforme se transcreve a seguir:

Nossa visão é transformar vidas por meio da educação ao reconhecer seu importante papel como principal impulsionador para o desenvolvimento e para o alcance de outros ODS propostos. Comprometemo-nos, em caráter de urgência, com uma agenda de educação única e renovada, que seja holística, ousada e ambiciosa, que não deixe ninguém para trás. Essa nova visão é inteiramente captada pelo ODS 4 "Assegurar a educação inclusiva e equitativa de qualidade, e promover oportunidades de aprendizagem ao longo da vida para todos" e suas metas correspondentes.

Com essa visão, transformadora e universal, percebem-se as "questões inacabadas" da agenda de EPT e ODM relacionadas à educação e também se abordam desafios globais e nacionais da educação. Ela é inspirada por uma visão humanista da educação e do desenvolvimento, com base nos direitos humanos e na dignidade; na justiça social; na inclusão; na proteção; na diversidade cultural, linguística e étnica; e na responsabilidade e na prestação de contas compartilhadas.

Reafirmamos que a educação é um bem público, um direito humano fundamental e a base que garante a efetivação de outros direitos. Ela é essencial para a paz, a tolerância, a realização humana e o desenvolvimento sustentável. Reconhecemos a educação como elemento-chave para atingirmos o pleno emprego e a erradicação da pobreza. Concen-

\footnotetext{
${ }^{12}$ Cfr. ROHLING, Marcos; VALLE, Ione Ribeiro. Princípios de Justiça e Justiça Escolar: a educação multicultural e a equidade. Op. cit., p. 386-409.
} 


\section{Democracia}

traremos nossos esforços no acesso, na equidade e na inclusão, bem como na qualidade e nos resultados da aprendizagem, no contexto de uma abordagem de educação ao longo da vida. ${ }^{13}$

Pode-se observar, de forma clara, o objetivo de elevar a educação ao patamar da verdadeira justiça social, para que a própria democracia seja realizada, consubstanciando também uma medida de pacificação social. $O$ acesso à educação é reconhecidamente um direito humano, assim como fundamental no ordenamento jurídico pátrio. Ademais, a educação de qualidade, inclusiva e equitativa, é um dos Objetivos do Desenvolvimento Sustentável, preconizados como agenda mundial adotada durante a Cúpula das Nações Unidas em 2015.

Ressalte-se, igualmente, o raciocínio de Hoopgood e Van Leeuwen (2019) para a transposição dos preceitos anteriormente abordados, de forma prática, ao processo educacional, conforme se transcreve na sequência:

Exposing children to democratic and human rights standards means that there can be free discussion in the classroom. It is vital to be able to listen to others and try to understand how they see the world. The ability and habit of seeing things through one's own eyes and experiences, but also to see and understand the way others see the same things, is intrinsic to good education. Human rights standards are constant and universal, but understanding their full meaning comes through their application in specific circumstances. This is essential if transitions to democracy and the resolution of conflicts in society are to be successful and sustainable. It is not automatic that understanding of human rights will be inculcated, but it is essential that this understanding is nurtured in schools. This depends on curriculum content but also teaching methods. ${ }^{14}$

Com efeito, em termos gerais, os cidadãos não têm contato com os ideais relacionados aos direitos humanos e têm uma ideia bastante nebulosa do que representam. Isto contribui de maneira decisiva para manter um abismo entre as disposições normativas sobre os direitos humanos (sejam as normas internas, sejam acordos e diretrizes internacionais) e o cumprimento efetivo destes direitos na vida prática dos homens.

Atualmente, apesar do importante papel da educação na sociedade, o que se observa é um programa de ensino e uma diretriz educacional orientados para a formação de profissionais a ingressarem no mercado de trabalho como importantes peças da engrenagem socioeconômica, sobretudo urbana. Todos os níveis de educação, desde a básica, dirigem sua linha

\footnotetext{
${ }^{13}$ UNESCO. Fórum Mundial de Educação 2015. Declaração de Incheon. Educação 2030: rumo a uma educação de qualidade, inclusiva e equitativa e à educação ao longo da vida para todos [Em linha]. Disponível em: https://unesdoc.unesco.org/ ark:/48223/pf0000233137_por. Acesso em: 24 mar. 2020.

${ }^{14}$ Leia-se em português, mediante tradução livre: "Expor as crianças a padrões democráticos e de direitos humanos significa que pode haver uma discussão livre na sala de aula. É vital poder ouvir os outros e tentar entender como eles vêem o mundo. A capacidade e o hábito de ver as coisas através dos próprios olhos e experiências, mas também de ver e entender a maneira como os outros vêem as mesmas coisas, é intrínseca à boa educação. Os padrões de direitos humanos são constantes e universais, mas a compreensão de todo o seu significado ocorre através da sua aplicação em circunstâncias específicas. Isso é essencial para que as transições para a democracia e a resolução de conflitos na sociedade sejam bemsucedidas e sustentáveis. Não é automático que a compreensão dos direitos humanos seja inculcada, mas é essencial que essa compreensão seja nutrida nas escolas. Isso depende do conteúdo do currículo, mas também dos métodos de ensino." Cfr. HOOPGOOD, Susan; VAN LEEUWEN, Fred. On Education \& Democracy - 25 Lessons from the Teaching Profession. Brussels: Education International, 2019. p. 19. ISBN: 978-92-95109-84-1.
} 
de ensino para matérias relevantes à formação técnica e objetiva, atendo-se a uma cartilha que não auxilia a resolver problemas próprios da dinâmica social e, ademais, inabilitando um desenvolvimento pleno do potencial humano.

É inegável que o aspecto prático e profissional não pode ser olvidado. Para a necessária evolução social, no entanto, nota-se a necessidade pungente de uma mudança de paradigma para que os educadores e os núcleos de ensino formem seres humanos plenamente capazes de se desenvolverem segundo suas particularidades, incluindo os aspectos humanistas e próprios do princípio da fraternidade, além da sustentabilidade. É necessário formar seres integrais, ativos e conscientes socialmente, como maneira de se alcançar uma sociedade verdadeiramente democrática, conforme já preconizado no cenário internacional, para um modelo educacional adequado ao século 21 e rumo a 2030.

\section{CONCLUSÃO}

A partir da análise proposta e estabelecida no presente estudo, pretendeu-se delinear o necessário raciocínio jurídico a alicerçar a política de ensino, de forma a considerar a educação como elemento basilar de um sistema democrático de direito e, em realidade, pressuposto fático para que a democracia possa, de fato, ser exercida. Além disso, o acesso à educação representa o meio pelo qual a própria dignidade da pessoa humana pode ser alcançada, por intermédio do pleno desenvolvimento das potencialidades dos indivíduos e de sua autodeterminação.

Conforme objetivou-se demonstrar, porém, a educação é reconhecida como direito humano no cenário internacional, bem como é a necessária inclusão da pauta humanística nos programas de ensino, tanto de forma a integrar a estrutura organizativa das políticas públicas e da estrutura do modelo educativo, quanto a ser considerado conteúdo imprescindível do ensino objetivo.

A proposta de se recordar do princípio da fraternidade como moderador e modulador da igualdade e da liberdade, mas também como princípio objetivamente válido na esfera pública, reforça a consideração dos direitos humanos na política e no campo jurídico, com reflexo necessário na seara educativa. O ensino humanista é fraternal e também humanitário, sem olvidar-se que a fraternidade transcende as questões associadas a este último vocábulo.

Por fim, após delinear-se os fundamentos da Declaração Universal dos Direitos Humanos, buscou-se trazer ao debate os pontos objetivos do marco de ação adotado pela comunidade internacional até 2030, desenvolvido no âmbito do Fórum Mundial de Educação e, igualmente, liderado pela Organização das Nações Unidas, rumo a uma educação de qualidade inclusiva e equitativa. Tais ideais são tecnicamente relevantes para não se perder de vista a sua aplicabilidade, pois, sobretudo, constituem-se conceitos fundamentais a integrarem de forma ampla as políticas públicas de ensino e sua execução no campo social.

\section{REFERÊNCIAS}

AMAYA, Amalia. "La Relevancia de la Fraternidad”. In: Yale Law School [Em linha], p. 5. Disponível em: https:// law.yale.edu/sites/default/files/area/center/kamel/sela17_amaya_cv_sp.pdf. Acesso em: 24 mar. 2020.

BRITTO, Carlo Ayres. O humanismo como categoria constitucional. 2ª reimpressão. Belo Horizonte: Ed. Fórum, 2012. 


\section{Humanos e \\ Democracia}

CUNHA, Paulo Ferreira. "Do Direito Natural ao Direito Fraterno". In: Revista de Estudos Constitucionais, Hermenêutica e Teoria do Direito (RECHTD), jan./jun, 2009, p. 78-86. ISSN: 2175-2168. Disponível em: http://www. revistas.unisinos.br/index.php/RECHTD/article/view/5138. Acesso em: 23 mar. 2020.

GONZALEZ, Roberto Veiga. "Entrevista al Profesor Antonio María BAGGIO". In: El horizonte de la fraternidade [Em linha]. Disponível em: http://www.uca.edu.ar/uca/common/grupo75/files/antonio_baggio.pdf. Acesso em: 15 fev. 2020.

HOOPGOOD, Susan; VAN LEEUWEN, Fred. On Education \& Democracy - 25 Lessons from the Teaching Profession. Brussels: Education International, 2019. ISBN: 978-92-95109-84-1.

ONU. Organização das Nações Unidas. Declaração Universal dos Direitos do Homem [Em linha], 1948. Disponível em: https://nacoesunidas.org/wp-content/uploads/2018/10/DUDH.pdf. Acesso em: 15 mar. 2010.

PERCIO, Enrique del. "Fraternidad, conflicto y realismo político. Claves para pensar la integración desde América Latina”. In: Teoría y Praxis, n. 21, jun./dic. 2012. Disponível em: http://rd.udb.edu.sv:8080/jspui/bitstream/11715/857/1/1-fraternidad-conflicto-y-realismo-politico.pdf. Acesso em: 15 fev. 2020.

ROHLING, Marcos; VALLE, Ione Ribeiro. "Princípios de Justiça e Justiça Escolar: a educação multicultural e a equidade". Cadernos de Pesquisa, v. 46, n. 160. p. 386-409 abr./jun. 2016.

SARTORI, Giovani. La Democracia en Treinta Lecciones. México: Santillana Ediciones Generales, 2009.

UNESCO. Fórum Mundial de Educação 2015. Declaração de Incheon. Educação 2030: rumo a uma educação de qualidade, inclusiva e equitativa e à educação ao longo da vida para todos [Em linha]. Disponível em: https:// unesdoc.unesco.org/ark:/48223/pf0000233137_por. Acesso em: 24 mar. 2020. 